\title{
Radixin knockdown improves the accumulation and efficiency of methotrexate in tumor cells
}

\author{
ATSUSHI KAWASE ${ }^{1}$, YUTA INOUE ${ }^{1}$, SAYAKA NAKAZAKI $^{1}$, ERIKA KOIZUMI ${ }^{1}$ and MASAHIRO IWAKI ${ }^{1-3}$ \\ ${ }^{1}$ Department of Pharmacy, Faculty of Pharmacy; ${ }^{2}$ Pharmaceutical Research and Technology Institute; \\ ${ }^{3}$ Antiaging Center, Kindai University, Osaka 577-8502, Japan
}

Received January 28, 2019; Accepted May 2, 2019

DOI: $10.3892 /$ or.2019.7162

\begin{abstract}
The plasma membrane localization of efflux transporters, such as multidrug resistance-associated protein (MRP/ABCC), is governed by scaffold proteins, such as the ezrin/radixin/moesin (ERM) proteins. Reduction of the anchor function of ERM proteins in tumor cells may decrease the transport activity of efflux transporters, possibly leading to increased intracellular accumulation and efficiency of anticancer drugs as substrates of efflux transporters. The effect of the knockdown of ERM proteins was examined in multiple carcinoma cell lines on the transport activity of efflux transporters and on the intracellular accumulation and efficiency of methotrexate (MTX). Radixin knockdown in human liver cancer HepG2 cells, human lung carcinoma A549 cells, and human breast carcinoma MDA-MB-453 cells led to a significant reduction in the transport activity of multidrug resistance-associated protein 2 (MRP2). The plasma membrane localization of MRP2 was significantly decreased by radixin knockdown in HepG2 cells. Increases in the accumulation and cytotoxicity of MTX in HepG2 cells treated with siRadixin were observed compared with control or siNegative. An in vivo study revealed that siRadixin treatment improved the efficiency of MTX in tumor-bearing mice. In conclusion, the present study provides information on radixin as a target molecule for the modulation of MRP activity in tumor cells.
\end{abstract}

\section{Introduction}

The multidrug resistance toward anticancer drugs caused by efflux transporters, such as multidrug resistance-associated protein (MRP/ABCC), P-glycoprotein (P-gp/ABCB1), and breast cancer resistance protein (BCRP/ABCG2), is a barrier to effective chemotherapy. The increased activities of these

Correspondence to: Dr Atsushi Kawase, Department of Pharmacy, Faculty of Pharmacy, Kindai University, 3-4-1 Kowakae, Higashi-osaka, Osaka 577-8502, Japan

E-mail: kawase@phar.kindai.ac.jp

Key words: tumor, multidrug resistance, transporter, radixin, scaffold protein transporters accompanying the malignant progression of tumor cells results in the reduction of intracellular drug concentrations in the tumors. The plasma membrane localization of efflux transporters is important for transport activity, as well as the expression levels of efflux transporters. The plasma membrane localization of efflux transporters is governed by scaffold proteins, such as the ezrin/radixin/moesin (ERM) proteins. For example, the interaction of MRP2 with ezrin and/or radixin causes the localization of MRP2 in the canalicular membrane in hepatocytes (1-3). Ezrin and moesin are involved in the plasma membrane localization of P-gp in brain capillary cells $(4,5)$. ERM proteins activated via phosphorylation by Rho-kinase (6) and cholecystokinin- 8 (7), function as anchoring proteins for efflux transporters and $\mathrm{Na}^{+}-\mathrm{H}^{+}$ exchanger regulatory factor 1 (8). Some reports have shown that ERM proteins are involved in the localization of transporters in tumor cells, as well as in normal tissues (9-11).

Thus, reduction of the anchor function of ERM proteins in tumor cells may decrease the transport activity of efflux transporters, possibly leading to increased intracellular accumulation and efficiency of anticancer drugs as substrates of efflux transporters. However, it is unclear whether ERM proteins can be used as target molecules for overcoming multidrug resistance in tumor cells.

Therefore, the effect of the knockdown of ERM proteins on the transport activities of MRP2, P-gp and BCRP was examined in multiple carcinoma cell lines, and on the intracellular accumulation and efficiency of methotrexate (MTX) as an anticancer drug.

\section{Materials and methods}

Ethical approval. The study protocol was approved by the Committee for the Care and Use of Laboratory Animals of the School of Pharmacy of Kindai University (Osaka, Japan).

Chemicals and reagents. Silencer Select siRNA for human ezrin (s14796), human radixin (s11899), human moesin (s8984), and Stealth RNAi siRNA negative control, Lipofectamine RNAiMAX Transfection Reagent, Opti-MEM I, BCA protein assay kit, Mem-PER Eukaryotic Membrane Protein Extraction Kit, and D-luciferin monosodium salt were obtained from Thermo Fisher Scientific, Inc. (Waltham, MA, USA). Rabbit monoclonal anti-rat ezrin (EP886Y; cat. no. ab40839), rabbit 
monoclonal anti-radixin antibody (EP1862Y; cat. no. ab52495) and rabbit monoclonal anti-moesin antibody (EP1863Y. cat. no. ab52490) (all from Abcam, Cambridge, UK), mouse monoclonal anti- $\beta$-actin antibody (cat. no. AM00194PU-N; Acris Antibodies $\mathrm{GmbH}$, Herford, Germany), peroxidase-labeled anti-rabbit IgG antibody (cat. no. ab214880) and peroxidase-labeled anti-mouse IgG antibody (cat. no. ab97040; both from Abcam), and peroxidase-labeled anti-mouse $\operatorname{IgG}$ antibody (cat. no. 5220-0341; KPL, Gaithersburg, MD, USA) were commercially obtained. For assay of transport activities, 5(6)-carboxy-2',7'-dichlorofluorescein diacetate promoiety (CDFDA, a precursor of MRP substrate (CDF); Sigma-Aldrich; Merck KGaA, Darmstadt, Germany), MTX (an MRP substrate) and Rhodamine 123 (R123, a P-gp substrate; both from Wako Pure Chemical Industries, Osaka, Japan), Hoechst 33342 hydrochloride (H33342, a BCRP substrate; Cayman Chemical, Ann Arbor, MI, USA), MK571 sodium salt hydrate (an MRP inhibitor; Sigma-Aldrich; Merck KGaA), verapamil (Nacalai Tesque, Inc., Kyoto, Japan) and Ko143 (MedChemExpress, Monmouth Junction, NJ, USA) were used. RIPA lysis buffer, including protease inhibitors, was obtained from Santa Cruz Biotechnology, Inc. (Dallas, TX, USA). For LC-MS/MS-based targeted proteomics, MS grade porcine pancreatic trypsin and OASIS HLB were obtained from Wako Pure Chemicals and Waters Corporation (Milford, MA, USA), respectively. Sepasol RNA I Super G and MTT cell count kits were purchased from Nacalai Tesque, Inc. In vivo jetPEI was obtained from Polyplus-transfection ${ }^{\circledR}$ (New York, NY, USA). ECL Prime blocking reagent, Hybond-P polyvinylidene difluoride membranes and the ECL Prime Western Blotting Detection system were purchased from GE Healthcare (Milwaukee, WI, USA). All other chemicals and solvents were of the highest purity commercially available or of mass spectrometry grade.

Cell culture and transfection of siRNA. Human liver cancer HepG2 cells, human lung carcinoma A549 cells, and human breast carcinoma MDA-MB-453 cells were obtained from the RIKEN Cell Bank (Ibaraki, Japan). Cells were maintained in Dulbecco's modified Eagle's medium (DMEM; Nacalai Tesque, Inc.) supplemented with $10 \%$ fetal bovine serum (FBS; $100 \mathrm{U} / \mathrm{ml}$ penicillin, and $100 \mu \mathrm{g} / \mathrm{ml}$ streptomycin at $37^{\circ} \mathrm{C}$ in the presence of $5 \% \mathrm{CO}_{2}$ and $95 \%$ air.

Cells were seeded at $1 \times 10^{5}$ cells/well onto a 24 -well plate (Sumitomo Bakelite Co., Ltd., Tokyo, Japan), and were transfected with siRNA (siEzrin, siRadixin, siMoesin, or siNegative, $5 \mathrm{pmol} / \mathrm{well}$ ) complexed with Lipofectamine RNAiMAX in Opti-MEM. The medium was replaced with fresh DMEM $48 \mathrm{~h}$ after transfection and the cells were used in the downstream experiments.

Evaluation of siRNA knockdown by real-time reverse transcription polymerase chain reaction (RT-PCR) and western blotting. mRNA and protein expression levels were assessed using RT-PCR and western blotting, as previously described $(12,13)$. Cells treated with siRNA for $48 \mathrm{~h}$ were washed twice with cold phosphate-buffered saline (PBS). Total RNA was extracted from each sample and reverse-transcribed to complementary DNA. PCRs were incubated at $95^{\circ} \mathrm{C}$ for $10 \mathrm{sec}$, and then amplified at $95^{\circ} \mathrm{C}$ for $5 \mathrm{sec}, 55^{\circ} \mathrm{C}$ for $20 \mathrm{sec}$, and $72^{\circ} \mathrm{C}$ for $31 \mathrm{sec}$ for 40 cycles. After RIPA buffer was added to the cells, the cells were collected by cell scrapers. Cells were sonicated for $30 \mathrm{sec}$ and were centrifuged at $14,000 \mathrm{xg}$ for $15 \mathrm{~min}$ at $4^{\circ} \mathrm{C}$. The protein concentrations in the supernatant were determined using a BCA protein assay kit. Sodium dodecyl sulfate-polyacrylamide gel electrophoresis (SDS-PAGE) was performed using 7.5\% e-Pagell (ATTO Corp., Tokyo, Japan) and $20 \mu \mathrm{g}$ of proteins/well. Resolved proteins were transferred onto Hybond-P polyvinylidene difluoride membranes and subjected to semi-dry blotting using a Trans-blot SD (Bio-Rad Laboratories, Hercules, CA, USA). After a membrane blocking in a $5 \%(\mathrm{w} / \mathrm{v})$ solution of ECL Prime blocking reagent in PBS for $1 \mathrm{~h}$ at room temperature, immunoreactive ezrin, radixin, moesin, and $\beta$-actin were detected using antibodies, and an ECL Prime Western Blotting Detection system. Primary antibodies and secondary antibodies were used for immunoblotting at a 1:1,000 and 1:10,000 dilution for $1 \mathrm{~h}$ each, respectively. The densitometric intensity of each band was detected with Ez capture and was calculated using CS analyzer 3 (both from ATTO Corp.).

Transporter activity assays. CDFDA $(10 \mu \mathrm{M}), \operatorname{MTX}(100 \mu \mathrm{M})$, $\mathrm{R} 123(50 \mu \mathrm{M})$ and $\mathrm{H} 33342(10 \mu \mathrm{M})$ with or without each inhibitor (50 $\mu \mathrm{M}$ MK571, $50 \mu \mathrm{M}$ verapamil and $10 \mu \mathrm{M}$ Ko143) were added $30 \mathrm{~min}$ before the cells were treated with siRNA for $48 \mathrm{~h}$. All transporter substrates were initially dissolved in dimethyl sulfoxide (DMSO). The final concentration of DMSO in the medium was $<0.5 \%$. After a $1 \mathrm{~h}$-incubation for CDFDA, MTX and H33342 and a 2 h-incubation for R123, the cells were washed twice with PBS. Then, $100 \mu 1$ of $1 \mathrm{M} \mathrm{NaOH}$ was added to lyse the cells, and the fluorescence intensity in the cells was measured using a fluorescence microplate reader (SH-9000; Corona Electric Co., Ibaraki, Japan) at Ex/Em wavelengths of $495 / 530 \mathrm{~nm}$ for CDF, 480/530 nm for R123, and $355 / 460 \mathrm{~nm}$ for H33342. The determination of MTX concentrations in the cell lysates was performed by liquid chromatography-tandem mass spectrometry (LC-MS/MS) as previously described (14). The LC-MS/MS equipment consisted of an LC system (UltiMate 3000 series) and a TSQ Endura Triple Quadrupole Mass Spectrometer with electrospray ionization (both from Thermo Fisher Scientific, Inc.). For data recording and analysis, Finnigan XCalibur software version 3 (Thermo Fisher Scientific, Inc.) was used.

Determination of the expression of MRP2, $P$-gp and BCRP in the cytoplasm and plasma membrane by targeted proteomics. Cytoplasm and plasma membrane proteins were extracted from HepG2 cells transfected with siRNA using a Mem-PER Eukaryotic Membrane Protein Extraction Kit. Proteins $(10 \mu \mathrm{g})$ diluted in $25 \mu \mathrm{l}$ of phase transfer surfactant buffer were reduced with $10 \mu \mathrm{M}$ dithiothreitol at room temperature for $30 \mathrm{~min}$. Free cysteines were alkylated in $42 \mu \mathrm{M}$ iodoacetamide at room temperature for $20 \mathrm{~min}$. A total of $50 \mu \mathrm{M}$ ammonium bicarbonate and $1 \mu \mathrm{g}$ of trypsin was added to the cell lysates. After trypsin digestion at $37^{\circ} \mathrm{C}$ for $18 \mathrm{~h}, 10 \mathrm{pmol}$ of isotope-labeled peptides were added. The digested samples were desalted by OASIS HLB. The eluted samples were dried under vacuum at $50^{\circ} \mathrm{C}$ and were resuspended in $100 \mu 1$ of the initial mobile phase $(4.5 \%$ acetonitrile with $0.1 \%$ formic acid). Peptides were separated on a reversed-phase column (AdvanceBio Peptide Map C18, 2.1x150 $\mu \mathrm{m}, 2.7 \mu \mathrm{m}$; Agilent Technologies, Inc., Santa Clara, CA, USA). The column 
temperature was set at $50^{\circ} \mathrm{C}$ and the autosampler was maintained at $4^{\circ} \mathrm{C}$. The mobile phase (A: $0.1 \%$ formic acid in water; B: $0.1 \%$ formic acid in $90 \%$ acetonitrile) was pumped at a flow rate of $0.1 \mu \mathrm{l} / \mathrm{min}$. The column was conditioned at $5 \%$ mobile phase B. From 2 to 26 min, mobile phase B increased linearly from 5 to $60 \%$. From 26 to 27 min, mobile phase B increased linearly to $98 \%$. From 28 to $35 \mathrm{~min}$, the mobile phase was maintained at $5 \%$ mobile phase B. The peptide sequences of surrogate peptides determined in this study were as follows; LTIIPQDPILFSGSLR for MRP2, IATEAIENFR for P-gp, SSLLDVLAAR for BCRP, DLTDYLMK for $\beta$-actin, and IVEIPFNSTNK for $\mathrm{Na}^{+} / \mathrm{K}^{+}$ATPase. The protein expression levels of MRP2, P-gp and BCRP in the cytoplasm and plasma membrane proteins were corrected by the intensities of surrogate marker peptides of $\beta$-actin and $\mathrm{Na}^{+} / \mathrm{K}^{+}$-ATPase, respectively (15-17).

Evaluation of the cytotoxicity of MTX by MTT assay. MTX $(100 \mu \mathrm{M})$ was added to HepG2 cells treated with siRadixin or siNegative and incubated for $48 \mathrm{~h}$. At $24 \mathrm{~h}$ after MTX treatment, $10 \mu \mathrm{l}$ of MTT cell count kit was added to the HepG2 cells for $3 \mathrm{~h}$. The absorbance was measured at $570 \mathrm{~nm}$ by Sunrise R (Tecan Group, Ltd., Männedorf, Switzerland).

Inoculation of tumor cells. Male BALB/c nu/nu (4-week-old, body weight 15-17 g) mice were purchased from Japan SLC (Shizuoka, Japan). The animals were housed in an air-conditioned room at $22 \pm 0.5^{\circ} \mathrm{C}$ and relative air humidity of $55 \pm 10 \%$ with a 12-h lighting schedule (7:00 a.m.-7:00 p.m.) and had free access to standard laboratory food (MF; Oriental Yeast Co., Ltd., Tokyo, Japan) and water on the light/dark schedule for a week before they were divided into each group. The total number of mice used in the present study was 67.

Firefly luciferase-expressing HepG2 cells (HepG2-Luc; JCRB Cell Bank, Tokyo, Japan) were trypsinized and suspended in Hank's buffered salt solution (HBSS). The cells (1x $10^{5}$ cells in HBSS) were inoculated by subcutaneous injection into the back of the mice.

Determination of the $m R N A$ levels of radixin in tumor-bearing mice by real-time reverse transcription polymerase chain reaction $(R T-P C R)$. Total RNA was extracted from the mouse tumors using Sepasol I super G, $48 \mathrm{~h}$ after treatment with $10 \mu \mathrm{g}$ of siRadixin or siNegative, complexed with in vivo jetPEI $(\mathrm{N} / \mathrm{P}=6)$. The mRNA expression was assessed using RT-PCR, as previously described $(18,19)$. The following primer sequences were used: Sense primer, 5'-TTTGGCTTCGTATGCTGT CC-3' and antisense primer, 5'-TGTTCCAAAACACGCTGT GG-3' for mouse radixin and sense primer, 5'-CATTGCTGA CAGGATGCAGAA-3' and antisense primer, 5'-CCGATCCAC ACAGAGTACTTGC-3' for mouse $\beta$-actin. Data were analyzed using the StepOne Real-Time PCR System (Thermo Fisher Scientific, Inc.), using the multiplex comparative method, as previously reported (20). The amount of target mRNA was normalized to $\beta$-actin as the internal control.

Accumulation of MTX in the tumors of tumor-bearing mice. HepG2-Luc suspended in HBSS was inoculated by subcutaneous injection into the back of the mice $\left(1 \times 10^{5}\right.$ cells $/$ mice $)$. At 1 week after inoculation of HepG2-Luc cells, the mice received injections of MTX using a 27-gauge needle for $10 \mathrm{sec}$ at $30 \mu \mathrm{g} / \mathrm{kg}$ into the tumors (the long axis at $\sim 4 \mu \mathrm{m}$ in tumor diameter) $48 \mathrm{~h}$ after treatment with $10 \mu \mathrm{g}$ of siRadixin or siNegative, complexed with in vivo jetPEI $(\mathrm{N} / \mathrm{P}=6)$. At $1 \mathrm{~h}$ after MTX treatment, the tumors were excised from mice euthanized by cervical dislocation and the blood samples were collected in heparinized tubes, and immediately centrifuged at $6,700 \mathrm{x} g$ for $10 \mathrm{~min}$ at $4^{\circ} \mathrm{C}$ to obtain plasma. The MTX levels in the tumors and plasma were determined by LC-MS/MS, as previously described (14). The ratio of the MTX level in the tumor to that in the plasma was used to indicate the accumulation of MTX in the tumor.

IVIS imaging. The IVIS imaging was performed according to the procedure of Puaux et al (21). Mice were injected intraperitoneally with D-luciferin at a dose of $150 \mu \mathrm{g} / \mathrm{kg}, 1,2$ and 3 weeks after inoculation with HepG2-Luc cells. The mice were anesthetized with isoflurane and placed on the imaging stage of the IVIS apparatus in the abdominal position with a continuous supply of isoflurane through the gas anesthesia manifold. Images were collected 15 min after D-luciferin injection using the IVIS Lumina XRMS Imaging System and photons emitted from the tumor and its surroundings were quantified using Living Image Software version 4 (both from PerkinElmer, Inc., Waltham, MA, USA).

Statistical analysis. The significance of differences between mean values was determined by Dunnett's test after analysis of variance (ANOVA) using GraphPad Prism software version 5 (GraphPad Software, Inc., La Jolla, CA, USA). Values of $\mathrm{P}<0.05$ were considered to indicate statistically significant differences.

\section{Results}

Efficiency of the knockdown of the ERM proteins in HepG2 cells by siRNA transfection. To confirm the efficiency of the knockdown of the ERM proteins in HepG2 cells by the siRNA, the mRNA and protein expression levels in the cell lysate were determined $48 \mathrm{~h}$ after siRNA transfection (Fig. 1). The knockdown of ERM proteins by siRNA was observed in the mRNA levels (Fig. 1A). The protein levels of the ERM proteins were significantly decreased by siRNA knockdown (Fig. 1B).

Efflux activity of MRP, P-gp, and BCRP in ERM proteinknockdown cells. To clarify the effect of ERM protein knockdown on the transport activity of MRP, P-gp and BCRP, the intracellular fluorescence intensities of transporter substrates in HepG2 cells with ERM protein knockdown were determined (Fig. 2). The knockdown of radixin, but not ezrin or moesin, resulted in a significantly higher intracellular accumulation of CDF compared with control HepG2 cells without ERM protein knockdown. There was little change in the intracellular accumulation of R123 and H33342 by ERM protein knockdown. Whether the effects of radixin knockdown on the intracellular accumulation of CDF were distinct to HepG2 cells (Fig. 3) was revealed. The radixin knockdown in A549 and MDA-MB-453 cells led to significant increases in intracellular CDF accumulation. 

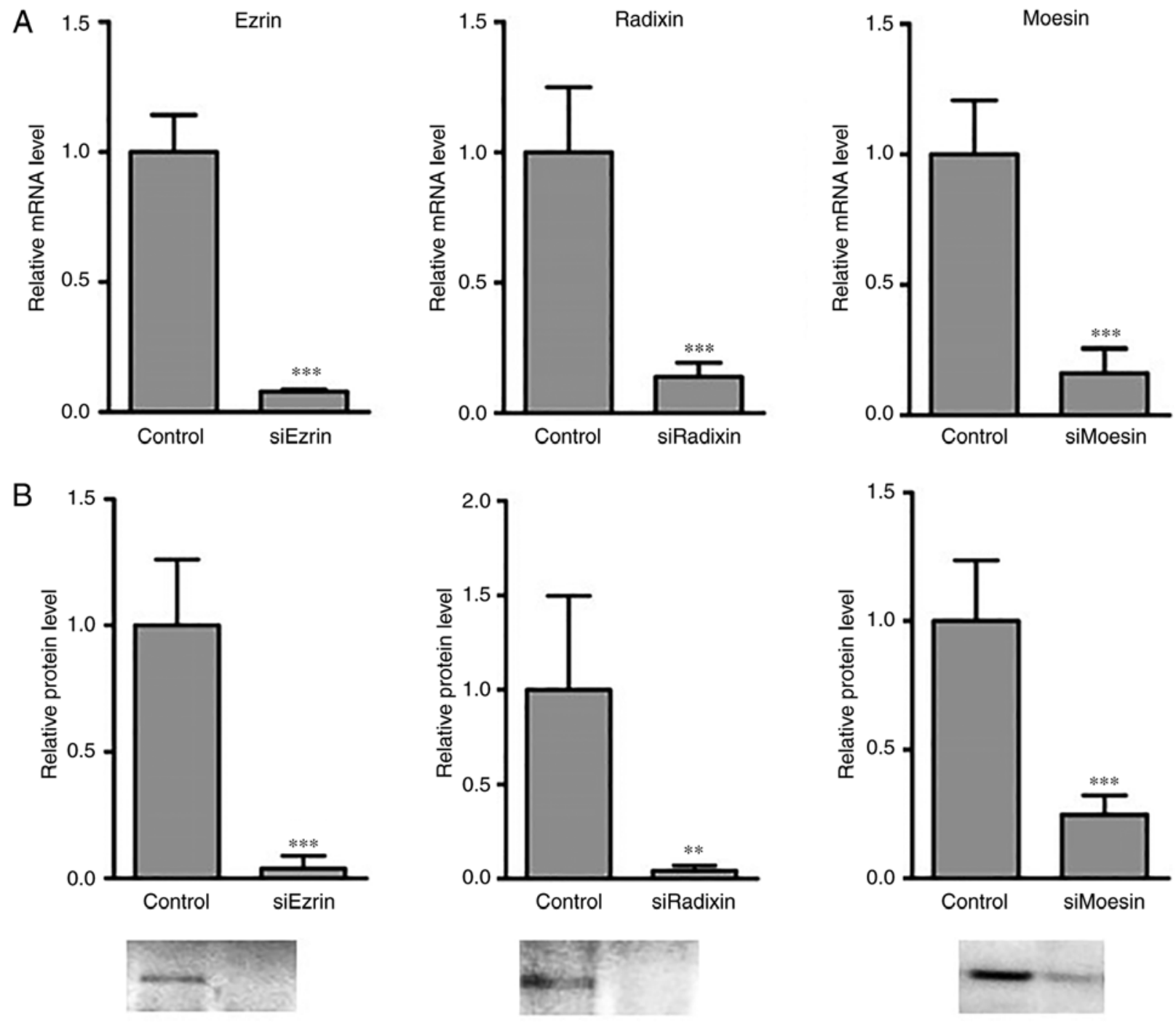

Figure 1. Relative (A) mRNA and (B) protein levels of ERM proteins in cell lysates $48 \mathrm{~h}$ after transfection with siEzrin, siRadixin, or siMoesin in HepG2 cells The results are expressed as the mean \pm SD of each group $(n=4)$. Significant differences $\left({ }^{* *} \mathrm{P}<0.01\right.$ and $\left.{ }^{* * * *} \mathrm{P}<0.001\right)$ between the control and siRNA treatments were observed. ERM, ezrin/radixin/moesin.

Levels of MRP2, $P$-gp and BCRP in radixin-knockdown cells. The levels of MRP2, P-gp, and BCRP in the cytoplasm and plasma membrane of HepG2 cells with radixin knockdown were determined (Fig. 4). The levels of MRP2, but not P-gp or $\mathrm{BCRP}$, in the plasma membrane were significantly decreased by radixin knockdown (Fig. 4). In the cytoplasm, the levels of MRP2, P-gp, and BCRP were unaltered by radixin knockdown.

Intracellular MTX accumulation and cytotoxicity in radixin-knockdown cells. The effect of radixin knockdown on intracellular MTX accumulation and cytotoxicity was examined (Fig. 5). The intracellular MTX accumulation was significantly increased by radixin knockdown compared with control and siNegative (Fig. 5A). The MTX cytotoxicity was also increased by radixin knockdown (Fig. 5B).

In vivo effects of radixin knockdown on the accumulation and efficiency of MTX. The in vivo knockdown efficiency of radixin in tumors after siRadixin treatment was determined (Fig. 6A). Significant decreases in radixin mRNA were observed in tumors, as well as in in vitro knockdown experiments. To clarify whether the treatments of siRadixin caused the topical knockdown of radixin, the radixin mRNA levels in liver were determined. The radixin mRNA levels in liver were unaltered between the control and siRadixin $48 \mathrm{~h}$ after intratumoral injection of siRNA complexed with in vivo jetPEI (data not shown). To clarify whether the radixin knockdown affected the accumulation of MTX in the tumors, the levels of MTX remaining in the tumors $1 \mathrm{~h}$ after MTX administration were determined (Fig. 6B). Higher concentrations of MTX were observed in the tumors of mice with radixin knockdown, although the plasma concentrations of MTX were unchanged by treatment of siRadixin. The anticancer effects of MTX after radixin knockdown were examined using in vivo imaging (Fig. 7). Tumor proliferation in the mice was suppressed by radixin knockdown. A significant decrease in the photon bioluminescence derived from HepG2-Luc cells was observed 3 weeks after inoculation of mice with HepG2-Luc cells. MTX alone revealed a lower anticancer effect compared with MTX with siRadixin. There was little effect with either siRadixin alone $\left(20.8 \times 10^{5}\right.$ photons/sec, $\left.\mathrm{n}=2\right)$ or in vivo jetPEI 

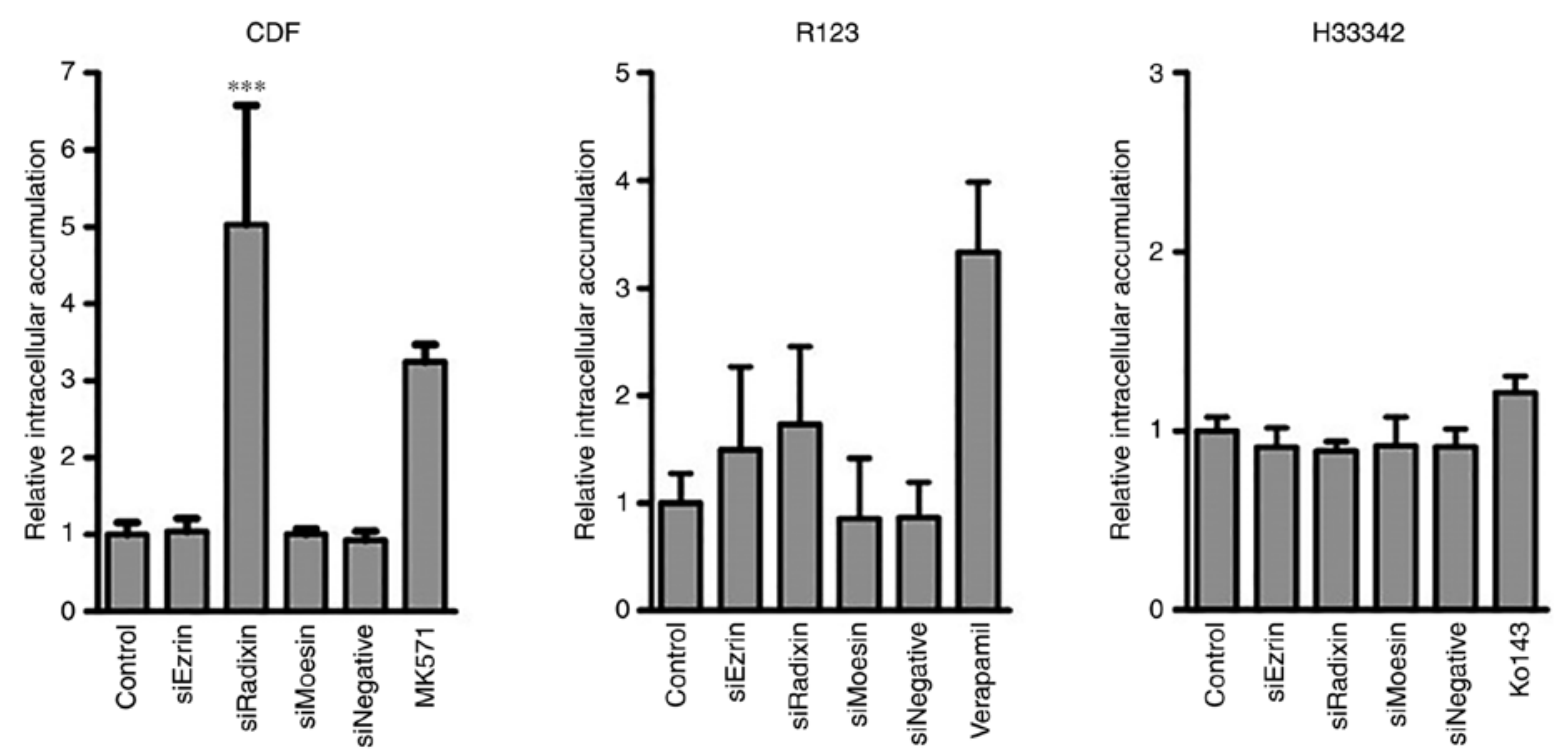

Figure 2. Relative intracellular accumulation of CDF, R123, and H33342 in HepG2 cells $48 \mathrm{~h}$ after transfection with siEzrin, siRadixin, or siMoesin. The results are expressed as the mean $\pm \mathrm{SD}$ of each group $(\mathrm{n}=4-6)$. Significant differences $\left({ }^{* * * *} \mathrm{P}<0.001\right)$ between the control and siRNA treatments were observed. CDF, 5(6)-carboxy-2',7'-dichlorofluorescein; R123, Rhodamine 123; H33342, Hoechst 33342.

A549

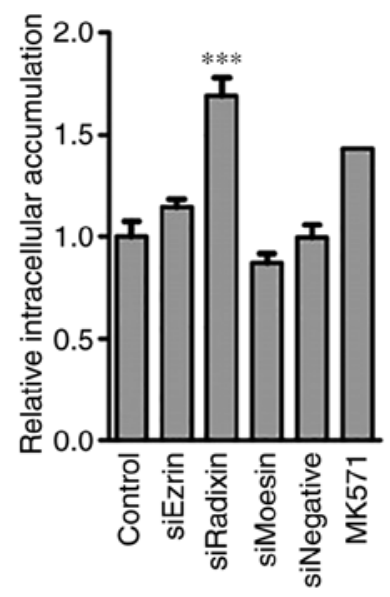

MDA-MB-453

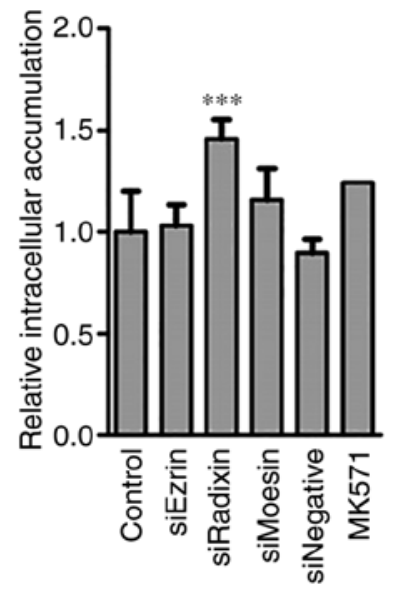

Figure 3. Relative intracellular accumulation of CDF in A549 and MDA-MB-453 cells $48 \mathrm{~h}$ after transfection with siEzrin, siRadixin, or siMoesin. The results are expressed as the mean $\pm \mathrm{SD}$ of each group $(\mathrm{n}=6)$. Significant differences $\left({ }^{* * *} \mathrm{P}<0.001\right)$ between the control and siRNA treatments were observed. CDF, 5(6)-carboxy-2',7'-dichlorofluorescein.

alone $\left(22.8 \times 10^{5}\right.$ photons $\left./ \mathrm{sec}, \mathrm{n}=2\right)$ on the relative intensity of the photon bioluminescence 3 weeks after inoculation of mice with HepG2-Luc cells.

\section{Discussion}

It was unclear whether ERM proteins could be target proteins for the modulation of efflux transporter activity in tumor cells, although ERM proteins have important roles in the regulation of transporter localization and activity in normal tissues. In the liver, radixin deficiency causes hyperbilirubinemia with loss of MRP2 from bile canalicular membranes (1). The plasma membrane localization and transport activity of MRP2 were inhibited by radixin knockdown in HepG2 cells (Figs. 2 and 4).
An in vivo study revealed the potential of radixin knockdown in tumor cells to improve the efficiency of MTX (Fig. 7). Radixin knockdown could promote the MRP2 internalization from the plasma membrane surface. However, the changes of absolute amounts of MRP2 in HepG2 cells remains unclear, because the protein expression levels were represented by relative amounts for control expression levels.

ERM proteins are involved in the distinct regulation of the localization and/or translation of transporters in normal tissues. For example, radixin knockout resulted in the reduction of P-gp expression and transport activity in the small intestine (22). Activation of ezrin led to apical localization of MRP2 in the small intestine (23). Radixin deficiency caused a loss of MRP2 from bile canalicular membranes (1). In the present study, it was examined whether ERM proteins participated in the plasma membrane localization and transport activity of transporters in tumor cells. The transport activity of MRP2 was significantly decreased by radixin knockdown in HepG2, A549, and MDA-MB-453 cells (Figs. 2 and 3), indicating that radixin is involved in the MRP2 function in tumor cells as well as in normal cells. Pokharel et al revealed that ERM proteins are involved in the regulation of the expression and function of P-gp in breast cancer cells (24). Yano et al demonstrated that the role of ERM proteins in the regulation of P-gp was different in Caco-2 and Caki-1 cells (11), indicating that the tissue-specific participation of ERM proteins in the regulation of P-gp in tumor cells was maintained as in the corresponding normal tissues. In HepG2 cells, the intracellular CDF accumulation was particularly increased by radixin knockdown compared with A549 cells and MDA-MB-453 cells, indicating a marked higher expression of MRP2 and/or higher interaction between radixin and MRP2 in the liver, because the inhibition of MRP activity by MK571 was insufficient in A549 and MDA-MB-453 cells. In addition to the regulation of the plasma membrane localization of transporters, ezrin was revealed to regulate the translational process of P-gp in HepG2 cells (25). However, in tumor cells, the participation of ezrin and moesin 

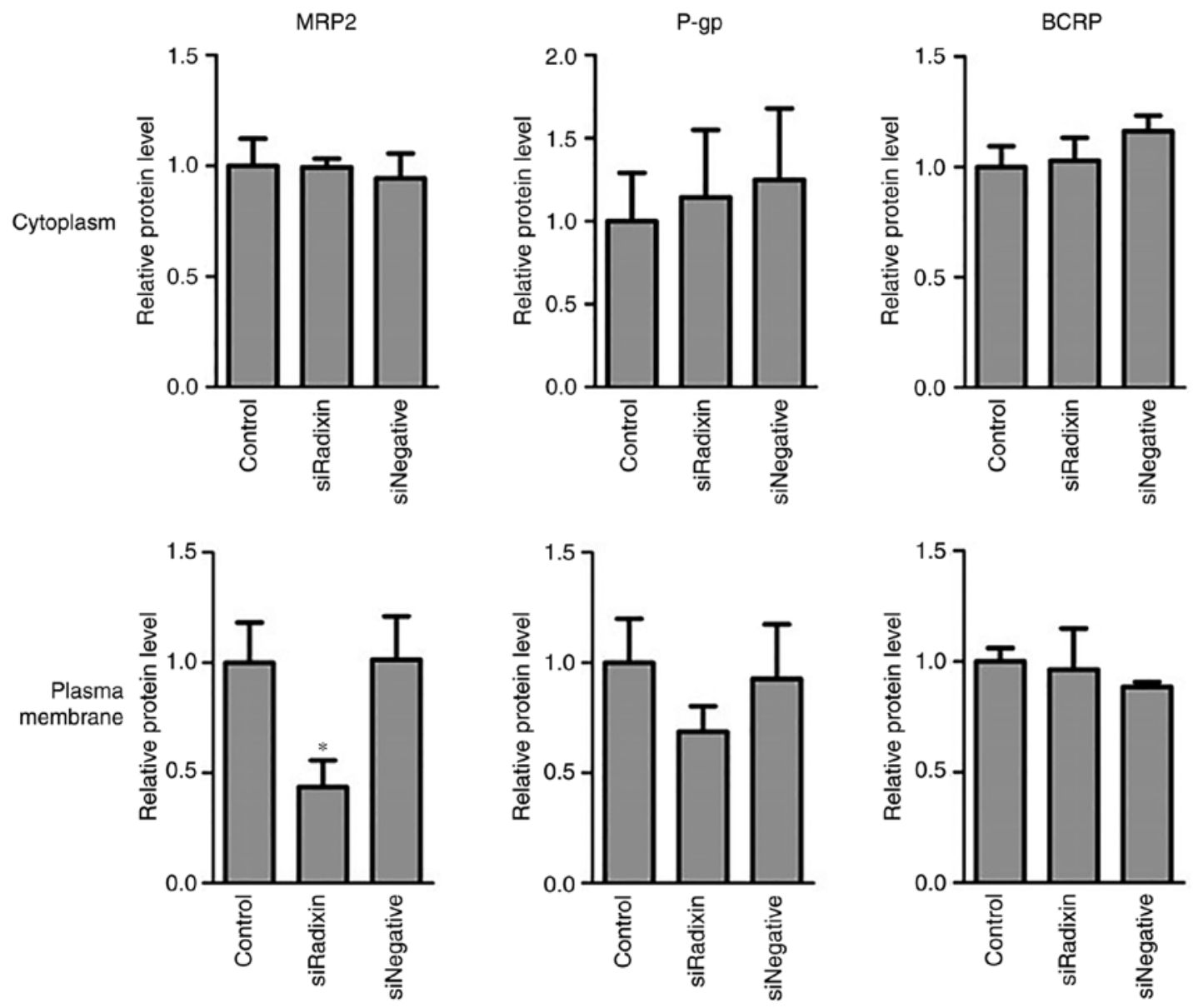

Figure 4. Relative levels of MRP2, P-gp, and BCRP in the cytoplasm and plasma membrane $48 \mathrm{~h}$ after transfection of siRadixin HepG2 cells. The results are expressed as the mean \pm SD of each group $(n=4)$. A significant difference $\left({ }^{*} \mathrm{P}<0.05\right)$ between the control and siRadixin treatment was observed. MRP2; multidrug resistance-associated protein 2; P-gp, P-glycoprotein; BCRP, breast cancer resistance protein.
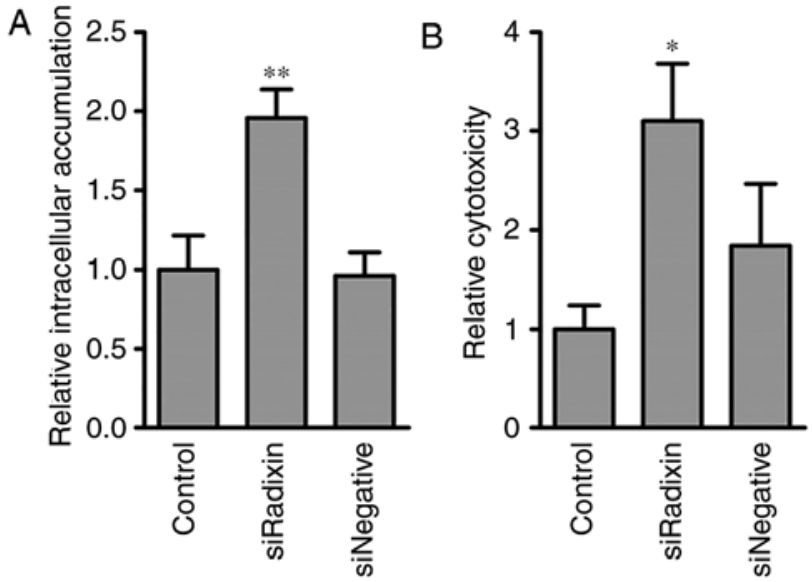

Figure 5. Relative intracellular accumulation of (A) MTX in HepG2 cells and (B) relative MTX cytotoxicity $48 \mathrm{~h}$ after transfection with siRadixin or siNegative in HepG2 cells. The results are expressed as the mean $\pm \mathrm{SD}$ of each group ( $\mathrm{n}=4-11)$. Significant differences $\left({ }^{*} \mathrm{P}<0.05\right.$ and $\left.{ }^{* *} \mathrm{P}<0.01\right)$ between the control and siRadixin treatment were observed. MTX, methotrexate.
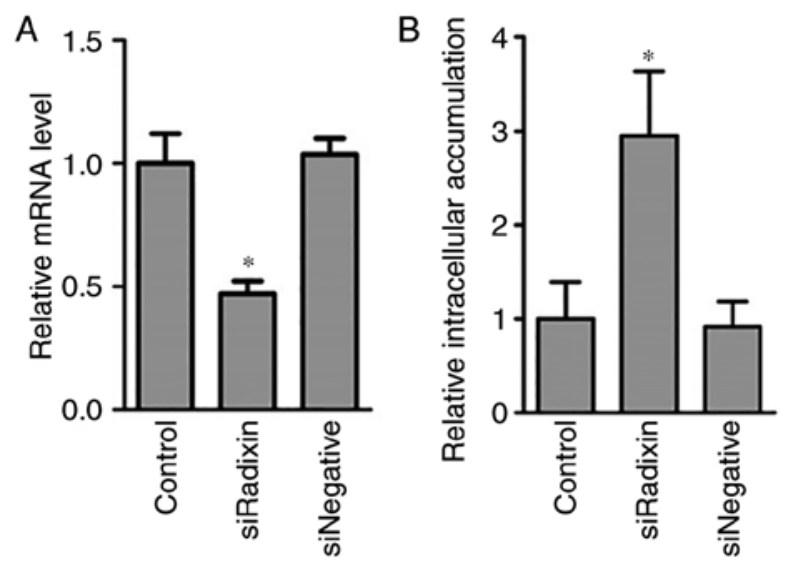

Figure 6. (A) Relative mRNA levels of radixin $48 \mathrm{~h}$ after treatment with siRadixin or siNegative, complexed with in vivo jetPEI and (B) MTX accumulation $1 \mathrm{~h}$ after MTX injections to mice treated with siRadixin or siNegative, complexed with in vivo jetPEI, for $48 \mathrm{~h}$. The results are expressed as the mean \pm SD of each group $(n=3)$. Significant differences $(* P<0.05)$ between the control and siRadixin treatment were observed. MTX, methotrexate. in the transport activity of MRP2, P-gp and BCRP may be reduced compared with radixin.

Multiple MRPs, including MRP1, MRP2 and MRP3, exhibit resistance to MTX exposure $(26,27)$. Both the MRP2 activity and expression levels in the plasma membrane of
HepG2 cells were significantly decreased by radixin knockdown. In preliminary experiments, the expression of MRP1 and MRP3 in the cytoplasm and plasma membrane were unaltered by radixin knockdown (data not shown). He et al demonstrated that radixin knockdown in human gastric carcinoma SGC-7901 

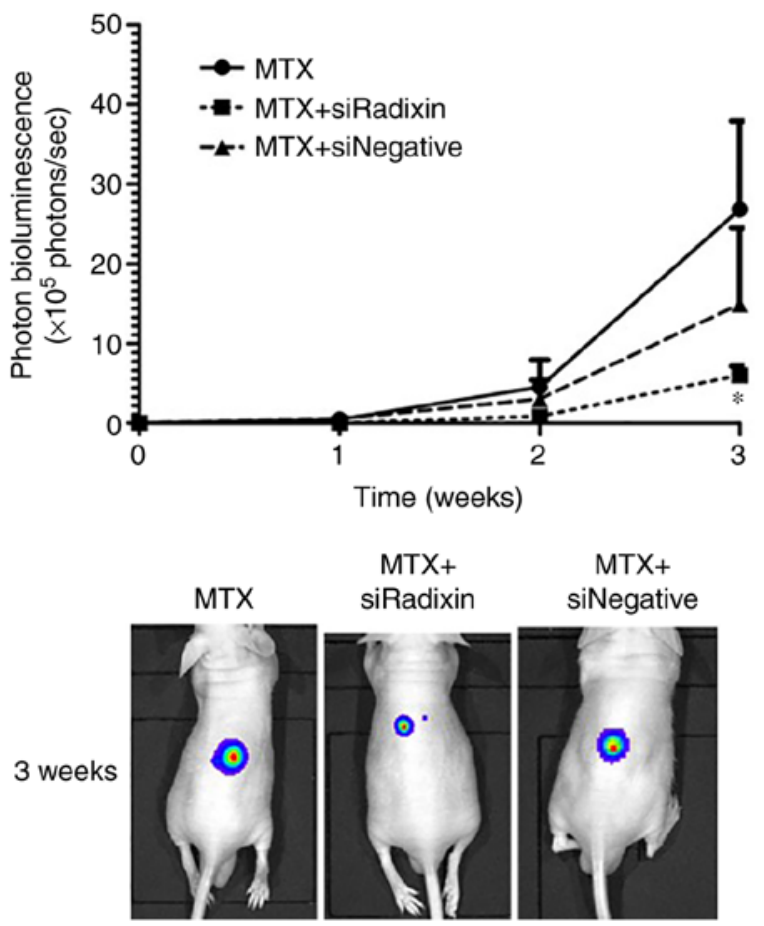

Figure 7. Photon bioluminescence of HepG2-Luc in mice treated with MTX with or without siRadixin or siNegative, complexed with in vivo jetPEI. The results are expressed as the mean \pm SD of each group $(n=3)$. Significant differences $\left({ }^{*} \mathrm{P}<0.05\right)$ between the control and siRadixin treatment were observed. MTX, methotrexate.

cells led to the specific knockdown of MRP2, not MRP1 or MRP3 (9). These findings were consistent with the decreased expression and activity of MRP2, compared with other MRP family members, after radixin knockdown in HepG2 cells.

There was little effect of ERM protein knockdown on the transport activity and expression levels of P-gp and BCRP in HepG2 cells (Figs. 2 and 4). In HepG2 cells, it was difficult to determine alterations in BCRP activity, because the intracellular accumulation of H33342 was slightly increased by Ko143. An improved evaluation system for BCRP activity is required to clarify the effect of ERM protein knockdown on the interactions between BCRP and ERM proteins. There was little effect of radixin knockdown on the expression of P-gp and BCRP in the cytoplasm and plasma membrane (Fig. 4). The changes in transporter expression by radixin knockdown corresponded with the alterations in the transport activity. Kano et al demonstrated that radixin knockdown in HepG2 cells decreased the protein expression of P-gp in plasma membrane (25). In our results, the activities of P-gp and the protein levels of P-gp in plasma membrane were tendency decreased, not statistically significant, although the detailed reasons for these differences remains unclear.

Based on the results of transport activity using typical fluorescent substrates for efflux transporters, radixin has potential as a target protein to improve the delivery efficiency of anticancer drugs recognized by MRP2. To clarify the effects of radixin knockdown on the efficiency of an anticancer drug in vitro and in vivo, the accumulation and efficiency of MTX as a typical anticancer drug which is an MRP substrate were examined (26-31). The intracellular accumulation of MTX was significantly increased by radixin knockdown (Figs. 5A and 6B). Increased cytotoxicity in
HepG2 cells treated with MTX was observed with radixin knockdown (Fig. 5B), indicating that the reduction of MRP2 activity in HepG2 cells led to an increase in the anti-cancer effects of MTX. In an in vivo study, tumor proliferation after inoculation of HepG2-Luc cells to mice was significantly delayed by radixin knockdown (Fig. 7). There was little effect with MTX alone, siRNA alone, or in vivo jetPEI alone, on the relative intensity of the photon bioluminescence. The dose of MTX was set to evaluate the effects of radixin knockdown on the tumor onset after ascertaining the anticancer effects of that dose of MTX on HepG2-Luc and referencing a previous study (32). The anticancer effects of MTX were enhanced possibly due to the reduction in the transport activity of MRP2 by radixin knockdown. Alternative sustained knockdown methods, such as viral vectors or peptides, should be used to increase the efficiency of MTX, although radixin is a useful target for the modulation of MRP2 in tumor cells. Further studies are required to clarify the effects of radixin knockdown on the other doses of MTX and on the anticancer efficiency of other drugs, such as doxorubicin, a substrate for MRP, P-gp, and BCRP $(33,34)$.

In conclusion, the present study provides information on radixin as a target molecule for the modulation of MRP activity in tumor cells. It would be useful to further investigate whether other transporter-associated proteins could be target proteins for the modulation of transporter functions.

\section{Acknowledgements}

Dr Victoria Muir edited a draft of this manuscript.

\section{Funding}

The present study was supported by JSPS KAKENHI grant no. 18K06806 from the Japanese Ministry of Education, Culture, Sports, Science, and Technology (MEXT). This research was also supported in part by the MEXT-Supported Program for the Strategic Research Foundation at Private Universities, 2014-2018 (S1411037).

\section{Availability of data and materials}

The datasets used during the present study are available from the corresponding author upon reasonable request.

\section{Authors' contributions}

AK and MI participated in the research design. AK, YI, SN and EK conducted the experiments and performed the data analysis AK and MI contributed to the writing of the manuscript. All authors read and approved the manuscript and agree to be accountable for all aspects of the research in ensuring that the accuracy or integrity of any part of the work are appropriately investigated and resolved.

\section{Ethics approval and consent to participate}

The study protocol was approved by the Committee for the Care and Use of Laboratory Animals of the School of Pharmacy of Kindai University (Osaka, Japan). 


\section{Patient consent for publication}

Not applicable.

\section{Competing interests}

The authors declare that they have no competing interests.

\section{References}

1. Kikuchi S, Hata M, Fukumoto K, Yamane Y, Matsui T, Tamura A, Yonemura S, Yamagishi H, Keppler D, Tsukita S and Tsukita S: Radixin deficiency causes conjugated hyperbilirubinemia with loss of Mrp2 from bile canalicular membranes. Nat Genet 31: 320-325, 2002.

2. Sekine S, Ito K, Saeki J and Horie T: Interaction of Mrp2 with radixin causes reversible canalicular Mrp2 localization induced by intracellular redox status. Biochim Biophys Acta 1812: 1427-1434, 2011

3. Chai J, Cai SY, Liu X, Lian W, Chen S, Zhang L, Feng X, Cheng Y, He X, He Y, et al: Canalicular membrane MRP2/ABCC2 internalization is determined by Ezrin Thr567 phosphorylation in human obstructive cholestasis. J Hepatol 63: 1440-1448, 2015.

4. Zhang Y, Dong J, Zhu X, Wang W and Yang Q: The effect of sphingomyelin synthase 2 (SMS2) deficiency on the expression of drug transporters in mouse brain. Biochem Pharmacol 82 287-294, 2011.

5. Kobori T, Fujiwara S, Miyagi K, Harada S, Nakamoto K, Nakagawa T, Takahashi $H$, Narita $M$ and Tokuyama $S$ : Involvement of moesin in the development of morphine analgesic tolerance through P-glycoprotein at the blood-brain barrier. Drug Metab Pharmacokinet 29: 482-489, 2014.

6. Matsui T, Maeda M, Doi Y, Yonemura S, Amano M, Kaibuchi K, Tsukita S and Tsukita S: Rho-kinase phosphorylates COOH-terminal threonines of ezrin/radixin/moesin (ERM) proteins and regulates their head-to-tail association. J Cell Biol 140: 647-657, 1998.

7. Yano K, Shimizu S, Tomono T and Ogihara T: Gastrointestinal hormone cholecystokinin increases P-glycoprotein membrane localization and transport activity in Caco-2 cells. J Pharm Sci 106: 2650-2656, 2017.

8. Vaquero J, Nguyen Ho-Bouldoires TH, Clapéron A and Fouassier L: Role of the PDZ-scaffold protein NHERF1/EBP50 in cancer biology: From signaling regulation to clinical relevance. Oncogene 36: 3067-3079, 2017.

9. He XJ, Wang WR, Zhang Y and Yang Q: The effect of radixin knockdown on the expression and efflux function of MRP2 in SGC-7901 cells. Eur J Pharm Sci 46: 426-434, 2012.

10. Zhang L, Xiao R, Xiong J, Leng J, Ehtisham A, Hu Y, Ding Q, $\mathrm{Xu} \mathrm{H}$, Liu S, Wang J, et al: Activated ERM protein plays a critical role in drug resistance of MOLT4 cells induced by CCL25. PLoS One 8: e52384, 2013.

11. Yano K, Otsuka K, Kato Y, Kawabata H, Ohmori S, Arakawa H and Ogihara T: Different regulation of P-glycoprotein function between Caco-2 and Caki-1 cells by ezrin, radixin and moesin proteins. J Pharm Pharmacol 68: 361-367, 2016.

12. Kawase A, Araki Y, Ueda Y, Nakazaki S and Iwaki M: Impact of a high-cholesterol diet on expression levels of Niemann-Pick C1-like 1 and intestinal transporters in rats and mice. Eur J Drug Metab Pharmacokinet 41: 457-463, 2016.

13. Kawase A, Sakata M, Yada N, Nakasaka M, Shimizu T, Kato Y and Iwaki M: Decreased radixin function for ATP-binding cassette transporters in liver in adjuvant-induced arthritis rats. J Pharm Sci 103: 4058-4065, 2014.

14. den Boer E, Meesters RJ, van Zelst BD, Luider TM, Hazes JM, Heil SG and de Jonge R: Measuring methotrexate polyglutamates in red blood cells: A new LC-MS/MS-based method. Anal Bioanal Chem 405: 1673-1681, 2013.

15. Uchida Y, Ohtsuki S, Kamiie J, Ohmine K, Iwase R and Terasaki T: Quantitative targeted absolute proteomics for 28 human transporters in plasma membrane of Caco-2 cell monolayer cultured for 2, 3, and 4 weeks. Drug Metab Pharmacokinet 30: 205-208, 2015.
16. Prasad B and Unadkat JD: Optimized approaches for quantification of drug transporters in tissues and cells by MRM proteomics. AAPS J 16: 634-48, 2014.

17. Harwood MD, Achour B, Russell MR, Carlson GL, Warhurst G and Rostami-Hodjegan A: Application of an LC-MS/MS method for the simultaneous quantification of human intestinal transporter proteins absolute abundance using a QconCAT technique. J Pharm Biomed Anal 110: 27-33, 2015.

18. Kawase A, Fujii A, Negoro M, Akai R, Ishikubo M, Komura H and Iwaki M: Differences in cytochrome P450 and nuclear receptor mRNA levels in liver and small intestines between SD and DA rats. Drug Metab Pharmacokinet 23: 196-206, 2008.

19. Kawase A, Yamada A, Gamou Y, Tahara C, Takeshita F, Murata K, Matsuda H, Samukawa K and Iwaki M: Increased effects of ginsenosides on the expression of cholesterol $7 \alpha$-hydroxylase but not the bile salt export pump are involved in cholesterol metabolism. J Nat Med 67: 545-553, 2013.

20. Livak KJ and Schmittgen TD: Analysis of relative gene expression data using real-time quantitative PCR and the 2(-Delta Delta C(T)) method. Methods 25: 402-8, 2001.

21. Puaux AL, Ong LC, Jin Y, Teh I, Hong M, Chow PK, Golay X and Abastado JP: A comparison of imaging techniques to monitor tumor growth and cancer progression in living animals. Int $\mathrm{J} \mathrm{Mol}$ Imaging 2011: 321538, 2011.

22. Yano K, Tomono T, Sakai R, Kano T, Morimoto K, Kato Y and Ogihara T: Contribution of radixin to P-glycoprotein expression and transport activity in mouse small intestine in vivo. J Pharm Sci 102: 2875-2881, 2013

23. Nakano T, Sekine S, Ito K and Horie T: Correlation between apical localization of Abcc2/Mrp2 and phosphorylation status of ezrin in rat intestine. Drug Metab Dispos 37: 1521-1527, 2009.

24. Pokharel D, Padula M, Lu J, Jaiswal R, Djordjevic S and Bebawy M: The role of CD44 and ERM proteins in expression and functionality of P-glycoprotein in breast cancer cells. Molecules 21: 290, 2016.

25. Kano T, Wada S, Morimoto K, Kato Y and Ogihara T: Effect of knockdown of ezrin, radixin, and moesin on P-glycoprotein function in HepG2 cells. J Pharm Sci 100: 5308-5314, 2011.

26. Kool M, van der Linden M, de Haas M, Scheffer GL, de Vree JM, Smith AJ, Jansen G, Peters GJ, Ponne N, Scheper RJ, et al: MRP3, an organic anion transporter able to transport anti-cancer drugs. Proc Natl Acad Sci USA 96: 6914-6919, 1999.

27. Hooijberg JH, Broxterman HJ, Kool M, Assaraf YG, Peters GJ, Noordhuis P, Scheper RJ, Borst P, Pinedo HM and Jansen G: Antifolate resistance mediated by the multidrug resistance proteins MRP1 and MRP2. Cancer Res 59: 2532-2535, 1999.

28. Zeng H, Chen ZS, Belinsky MG, Rea PA and Kruh GD: Transport of methotrexate (MTX) and folates by multidrug resistance protein (MRP)3 and MRP1: Effect of polyglutamylation on MTX transport. Cancer Res 61: 7225-7232, 2001.

29. Volk EL and Schneider E: Wild-type breast cancer resistance protein (BCRP/ABCG2) is a methotrexate polyglutamate transporter. Cancer Res 63: 5538-5543, 2003

30. Chen ZS, Robey RW, Belinsky MG, Shchaveleva I, Ren XQ, Sugimoto Y, Ross DD, Bates SE and Kruh GD: Transport of methotrexate, methotrexate polyglutamates, and 17beta-estradiol 17-(beta-D-glucuronide) by ABCG2: Effects of acquired mutations at R482 on methotrexate transport. Cancer Res 63: 4048-4054, 2003.

31. Vlaming ML, van Esch A, van de Steeg E, Pala Z, Wagenaar E, van Tellingen $\mathrm{O}$ and Schinkel $\mathrm{AH}$ : Impact of abcc2 [multidrug resistance-associated protein (Mrp) 2], abcc3 (Mrp3), and abcg2 (breast cancer resistance protein) on the oral pharmacokinetics of methotrexate and its main metabolite 7-hydroxymethotrexate. Drug Metab Dispos 39: 1338-1344, 2011.

32. Nakase Y, Hagiwara A, Kin S, Fukuda K, Ito T, Takagi T, Fujiyama J, Sakakura C, Otsuji E and Yamagishi H: Intratumoral administration of methotrexate bound to activated carbon particles: Antitumor effectiveness against human colon carcinoma xenografts and acute toxicity in mice. J Pharmacol Exp Ther 311: 382-387, 2004.

33. Choi $\mathrm{CH}$ : $\mathrm{ABC}$ transporters as multidrug resistance mechanisms and the development of chemosensitizers for their reversal. Cancer Cell Int 5: 30, 2005.

34. Chien AJ and Moasser MM: Cellular mechanisms of resistance to anthracyclines and taxanes in cancer: Intrinsic and acquired. Semin Oncol 35 (Suppl 2): S1-S14; quiz S39, 2008. 